https://doi.org/10.26512/pól.v9i17.26928

\title{
A REALIDADE OBJETIVA DA UTUPË COMO ALTERNATIVA AO CETICISMO EPISTEMOLÓGICO MODERNO
}

\author{
THE OBJECTIVE REALITY OF UTUPË AS AN ALTERNATIVE TO MODERN \\ EPISTEMOLOGICAL SKEPTICISM
}

\author{
Marina Burigo Guimarães Back \\ (marinabgback@gmail.com) \\ Munir Bazzi $i^{2}$ \\ (munirbazzi@gmail.com)
}

\begin{abstract}
RESUMO
O presente ensaio aborda a filosofia Yanomami, exposta na obra A queda do céu, a partir do conceito de utupë, traduzido pelos pesquisadores como imagem. Para muitos comentadores, tal conceito é a chave de compreensão da cosmo-ontologia Yanomami. Este trabalho argumenta em favor da originalidade da utupë se comparada ao paradigma ocidental de representação, de sua distinção em relação à Ideia platônica e de sua fecundidade ontológica e epistemológica. Do ponto de vista ontológico, o ensaio expõe o caráter de essência ou verdadeiro interior dos seres abarcado pela utupë, bem como sua eternidade e universalidade. No que concerne à epistemologia, o trabalho destaca a utupë como principal fonte epistêmica do xamanismo Yanomami e articula uma arrojada hipótese de pesquisa: a intuição sobrenatural, modalidade de conhecimento por apreensão direta da utupë, pode ser uma superação da fratura ontognoseológica subjacente à oposição sujeito-objeto e uma resposta ao sempre incômodo problema do ceticismo epistemológico.
\end{abstract}

Palavras-chave: Utupë. Xamanismo. Filosofia Yanomami. Ontologia. Epistemologia.

\begin{abstract}
This essay addresses the Yanomami philosophy, presented in the work The falling sky, based on the concept of utupë, translated by researchers as image. For many commentators, such concept is the key to understanding Yanomami cosmo-ontology. This paper argues for the originality of utupë when compared to the Western paradigm of representation, for its distinction from the Platonic Idea, and for its ontological and epistemological fecundity. From the ontological point of view, this essay exposes the essence or true interior character of beings embraced by utupë, as well as their eternity and universality.
\end{abstract}

\footnotetext{
${ }^{1}$ Graduanda em Filosofia pela Universidade Federal do Paraná (UFPR).

CV Lattes: http://lattes.cnpq.br/8380758406753103.

ORCID: https://orcid.org/0000-0002-5157-9409.

${ }^{2}$ Graduando em Filosofia pela Universidade Federal do Paraná (UFPR).

CV Lattes: http://lattes.cnpq.br/7965708999633830.

ORCID: https://orcid.org/0000-0002-9210-5138.
} 
Regarding epistemology, the study highlights utupë as the main epistemic source of Yanomami shamanism and articulates a bold research hypothesis: supernatural intuition, a mode of knowledge through direct apprehension of utupë, may be an overcoming of the ontognoseological fracture underlying the subject-object opposition and a response to the ever-uncomfortable problem of epistemological skepticism.

Keywords: Utupë. Shamanism. Yanomami Philosophy. Ontology. Epistemology.

\section{INTRODUÇÃO}

O caráter complexo, multifacetado e fecundo em linhas interpretativas do termo Yanomami итиё é frequentemente destacado pelos estudiosos da obra A queda do céu (ALBERT, 2014, pp. 239-242; VALENTIM, 2018, pp. 213-238). Os estudos inspirados em tal termo mostram que, acima de uma questão exegético-linguística, são mais frutíferos os esforços de compreensão de uma ideia-chave que descortina a original e rica cosmo-ontologia dos Yanomami.

Numa primeira aproximação puramente linguística, destacamos a nota de Albert dedicada a explicar que "as imagens fotográficas são designadas pelo termo utupë, que significa 'imagem corpórea, essência vital, forma mítica primordial' e, também, 'reflexo, sombra, eco, miniatura, réplica, reprodução, desenho"” (KOPENAWA; ALBERT, 2015, p. 621, nota 14). Julgamos que a riqueza conceitual do termo não pode ser encerrada em nenhuma das tentativas de tradução como equivalência, mas que o conjunto de tais tentativas oferece diferentes visadas que vão, gradualmente, auxiliando a construir o conceito, que "parece ser tão múltiplo quanto suas instâncias concretas de (trans-) figuração" (VALENTIM, 2018, p. 221). A opção pelo termo imagem foi motivada pela designação dada, pelos próprios Yanomami, de utupë a "todas as manifestações de nossa iconofilia (imagens de papel ou digitais, animadas ou não), representações plásticas diversas (desenhos, gravuras, pinturas, estátuas) ou modelos reduzidos (brinquedos e miniaturas)" (ALBERT, 2014, p. 240, trad. M. A. Valentim). Pesa sobre essa escolha a dilatada polissemia e a variegada trajetória, na filosofia ocidental, do termo “imagem”, fato que nos alerta para não incorrermos em transposições conceituais indevidas, mas sim envidar todos os esforços de compreensão quanto ao que realmente os Yanomami pretendem expressar por utupë.

É digna de nota, contudo, a problemática ambivalência do emprego de utupë, tanto para indicar realidades ditas "o verdadeiro centro, o verdadeiro interior" (KOPENAWA; ALBERT, 2015, p. 116), como também na acepção de "reflexo, sombra, eco, 
miniatura, réplica, reprodução, desenho", que segundo a metafísica ocidental interpretamos como tendo menos ser do que aquilo a que se vinculam. Estamos habituados a polissemias de sentidos afins, ou ao menos metaforicamente aproximados, e não a sentidos que parecem opostos: de um lado o mais real, de outro o menos. Somos então convidados a flexibilizar o juízo analítico, tradicionalmente regrado pela lógica de identidade e não contradição, e a tomar contato com um termo que pode designar tanto o mais como o menos real (em termos ocidentais), para com isso revelar um perspectivismo que diversifica e democratiza o estatuto de real.

Respeitando a fecundidade interpretativa que utupë oferece, optamos por avançar numa chave de leitura que confere a esse termo a acepção epistêmica e ontologicamente mais forte, qual seja, daquilo que possui maior realidade e verdade, a de "verdadeiro coração" das coisas. Desse modo, buscaremos oferecer uma interpretação da filosofia Yanomami cujas radicais consequências podem responder a problemas da metafísica ocidental, como o da impossibilidade do conhecimento das coisas em si na tradição kantiana. Com esse objetivo em vista, o trabalho será estruturado da seguinte maneira: apresentaremos a acepção forte de utupë - aquela que lhe atribui protagonismo ontológico e epistêmico -, para então contrastá-la com a Ideia platônica; em seguida, delinearemos o problema do subjetivismo na epistemologia moderna; e, finalmente, proporemos a intuição sobrenatural como hipótese de acesso às coisas em si mesmas, na condição de solução possível ao problema anteriormente exposto.

\section{FUNDAMENTAÇÃO}

\subsection{Utup $\ddot{e}$ em sentido forte}

Ao analisar as múltiplas acepções de utupë descritas por Albert, Valentim tece o seguinte comentário

[...] o conceito de imagem congrega significados aparentemente antagônicos: imagem como contida no corpo (vida), mas também como separada dele (alma); imagem como essência original (arquétipo), mas também como reflexo e reprodução (simulacro); imagem como forma das coisas (categoria), mas também como sujeito espiritual (pessoa). (VALENTIM, 2018, p. 220)

Do ponto de vista ontológico, podemos dizer que a acepção mais forte de utupë é a que encerra a existência independente de seres-imagens, notadamente 
aqueles que, "ao se tornarem xapiri, executam sua dança de apresentação para eles [os xamãs]" e que são descritos como "o verdadeiro centro, o verdadeiro interior dos animais que caçamos" (KOPENAWA; ALBERT, 2015, p. 116). Para Kopenawa (2015, p. 116-118), “todos os seres da floresta possuem uma imagem utupë", mas os que se tornam xapiri "são imortais" e "não podem desaparecer jamais”. São características, portanto, dos seres-imagens tornados xapiri sua condição de essências (verdadeiro interior) e sua eternidade, ao menos desde que nenhuma outra agência sobrenatural os destrua.

Segundo Albert, os xapiri estão na própria constituição do mundo fenomênico: "Esses seres-imagens corpusculares, espécies de quanta mitológicos, povoam livremente o mundo, marcado por uma incessante atividade de jogos, trocas e guerras que subjazem à dinâmica dos fenômenos visíveis" (ALBERT, 2014, p. 240, trad. M. A. Valentim). Os xapiri são, portanto, ontologicamente constitutivos do real, e tais imagens xamânicas, longe de serem meros eventos intrapsíquicos (representações, alucinações, imagens puramente mentais), são dotadas de objetividade cujo conhecimento descortina uma dimensão inaudita da realidade

O conceito Yanomami de utupë não pode ser reduzido à nossa noção de "imagem" enquanto representação figurada de uma realidade pré-existente sobre um meio qualquer (simulacrum). Além disso, ele não pode ser limitado ao registro de nossas "imagens mentais", imagens-miragens que ressaltam também da representação analógica, mas, desta vez, interior (phantasma). De fato, as imagens utupë dos seres primordiais descritas pelos xamãs com grande luxo de precisões estéticas o são, primeiramente, a título de percepções diretas de uma realidade exterior considerada como absolutamente tangível (o "ver" é aqui autenticamente um "conhecer"). (ALBERT, 2014, pp. 240-241, trad. M. A. Valentim)

A percepção direta das realidades objetivas - "absolutamente tangíveis" - constituídas pelas utupë é, portanto, "autenticamente um conhecer". O papel de fonte epistêmica desempenhado pelos xapiri é comentado por Davi Kopenawa ao longo de toda a obra A queda do céu. O contato com tais seres-imagens, na realidade, é descrito pelo autor xamã como a mais autêntica ou principal fonte de conhecimento

Eu não aprendi a pensar as coisas da floresta fixando os olhos em peles de papel. Vi-as de verdade, bebendo o sopro de vida de meus antigos com o pó de yãkoana que me deram. Foi desse modo que me transmitiram também o sopro dos espíritos que agora multiplicam minhas palavras e estendem meu pensamento em todas as direções. (KOPENAWA; ALBERT, 2015, p. 76) 
Kopenawa relata que os xamãs antigos exortam os mais novos a "responder ao chamado dos espíritos", pois, "se pararem de fazê-lo, ficarão ignorantes", e, numa consequência tão drástica quanto elucidativa da importância do contato com os xapiri, afirma que "perderão seu pensamento" (KOPENAWA; ALBERT, 2015, p. 75). Nessa passagem se estabelece a relação intrínseca entre os dados que apreendemos de nosso contato com os espíritos e a própria capacidade intelectiva, na medida em que é essa relação que nos permite conhecer verdadeiramente o mundo.

O processo de aquisição de conhecimento verdadeiro através do contato com os espíritos é bem explicitado no relato de que "[os xapiri] levam nossa imagem para o tempo do sonho. Por isso somos capazes de ouvir seus cantos e contemplar suas danças de apresentação enquanto dormimos. Essa é a nossa escola, onde aprendemos as coisas de verdade" (KOPENAWA; ALBERT, 2015, p. 77, grifo nosso). O interesse pela verdade é identificado pelo autor xamã como o motivo de seu contato com os espíritos: "Achei que seria bonito poder ver as coisas de verdade e assim, aos poucos, fui me afeiçoando aos xapiri" (Ibid., p. 103). Os xapiri, portanto, são a principal fonte epistêmica apontada por Kopenawa, e o transe xamânico no qual a imagem do xamã entra em contato direto com os seres-imagens xapiri é o protótipo do aprendizado das "coisas de verdade".

Por conseguinte, o sentido forte de utupë que queremos ressaltar para os objetivos do presente trabalho é o espectral e objetivo dos seres-imagens que são, ao mesmo tempo, constitutivos do universo e fontes epistêmicas primordiais do mesmo. A força a que aludimos, portanto, é ontológica e epistêmica. A utupë nesse sentido tem o mesmo peso filosófico dos átomos de Demócrito ou das mônadas de Leibniz: sua concepção explica a estrutura íntima do real, seu conhecimento é fundamental ao próprio conceito de verdade.

\subsection{Distinção entre utupë e a Ideia platônica}

Uma possível aproximação do conceito de utupë, ao menos no sentido forte que anteriormente destacamos, seria com o de Ideia platônica, visto que ambos estão no centro de uma teoria ontológica e epistemológica e que o próprio termo imagem usado na tradução de utupë induz a uma associação ao paradigma ocidental de representação. No entanto, os seresimagens distinguem-se marcadamente das Ideias platônicas e, como consequência, a filosofia Yanomami é distinta do platonismo e da teoria tradicional da representação. Tal filosofia pode, inclusive, subverter o paradigma representacional baseado na semelhança e apresentar uma visão de mundo na qual a transformação tem papel 
central: "Ser fantasma/espectro de outrem não é ser sua cópia, fiel ou degradada, mas sim sua imagem transformada, ser outro em relação a outrem, e não semelhante ao mesmo" (VALENTIM, 2018, p. 223).

Platão deixou claro o quanto sua visão de conhecimento distanciava-se de tudo o que fosse relacionado com a mutabilidade e multiplicidade ao propor que "[...] os filósofos são aqueles que são capazes de atingir aquilo que se mantém sempre do mesmo modo, e que aqueles que não são, mas se perdem no que é múltiplo e variável, não são filósofos [...]" (R. 484b 4-7, grifo nosso). Se a filosofia for reduzida à busca de Ideias imutáveis, o xamã é como que um antifilósofo. O potencial metamórfico, a sobrenaturalidade superlativa dos xapiri, o devir animal (yaroprai), o tornar-se outro, a espectralidade a um tempo tangível e fugidia, tudo isso escapa ao projeto platônico de investigação do absolutamente idêntico a si e imutável. Os filósofos, segundo Platão, são "apaixonados pelo saber que possa revelar-lhes algo daquela essência que existe sempre, e que não se desvirtua por acção da geração e da corrupção" ( $R$. 485b 1-3), ao passo que os xamãs estão em constante "comércio com a infinidade de agências, ao mesmo tempo inteligíveis e radicalmente outras, que se encontram disseminadas pelo cosmos" (VIVEIROS DE CASTRO, 2015, p. 38).

A distinção entre Ideia e utupë também é flagrante na radical divergência que Platão e Kopenawa mantêm em relação ao processo de sonhar. O filósofo ateniense assim se expressa

\begin{abstract}
Ora, quem acreditar que há coisas belas, mas não acreditar que existe a beleza em si nem for capaz de seguir alguém que o conduzisse no caminho do seu conhecimento, parece-te que vive em sonho ou na realidade? Repara bem. Por ventura sonhar não é quando uma pessoa, quer durante o sono, quer desperta, julgar que um objecto semelhante a outro não é uma semelhança, mas o próprio objeto com que se parece? (R. 476c $2-8)$
\end{abstract}

Essa passagem demonstra o desprezo de Platão pelo sonho, que é tido como experiência paradigmática do erro de tomar cópias pela realidade. Portanto, nada mais distante da verdade para Platão do que os sonhos, ao passo que para Kopenawa os mesmos são uma fonte epistêmica privilegiada: “Aos poucos ia virando fantasma e, quando anoitecia, sonhava sem parar. Então, podia ver as magníficas imagens dos ancestrais animais, dos espíritos do céu e dos rios" (KOPENAWA; ALBERT, 2015, pp. 97-98). Enquanto o autor ateniense entende o sonho como criação de cópias e simulacros na mente, o xamã tem na experiência onírica a libertação da utupë de sua pele (corpo) de modo a entrar em contato direto com outras utupë, especialmente os xapiri, de quem aufere verdadeiros conhecimentos (KOPENAWA; ALBERT, 2015, p. 616, nota 3). A utupë, ao contrário da Ideia 
somente acessível intelectualmente, pode, portanto, ser "hipervisível a 'olhos de espírito" (VALENTIM, 2018, p. 227).

Muito distinta do "imóvel e terrível museu dos arquétipos platônicos" (BORGES, 2011, p. 18), a cosmologia Yanomami é movida por metamorfoses nas quais a multiplicidade e o tornar-se outro estabelecem "uma inversão radical do platonismo: os simulacros são 'os verdadeiros maiores"” (VALENTIM, 2018, p. 224). Desse modo, a utupë, que é o "centro de gravidade da ontologia e da cosmologia Yanomami” (ALBERT, 2014, p. 239, trad. M. A. Valentim), diferencia-se em definitivo da Ideia platônica: de um lado a imagem potencialmente visível e tangível, múltipla, metamórfica, fundante da auto diferença; de outro, a forma inacessível aos sentidos, apenas inteligível, una, imutável e modelo por excelência do paradigma da semelhança.

\subsection{O problema do subjetivismo moderno}

À luz do conceito forte de utupë que ressaltamos neste trabalho, julgamos que pode ser apresentada uma proposta de solução para um dos principais problemas filosóficos da modernidade: a possibilidade do conhecimento real, e não de meras conjecturas, na relação sujeito-objeto. Ninguém expressou melhor a premência desse problema que o fundador da filosofia moderna ocidental, com base na premissa auto evidente de que o único fato da experiência de que não podemos duvidar é a atividade de nossa mente

Em certas coisas, como aquelas percebidas por intermédio dos sentidos, as coisas que percebemos e que nos parecem evidentes, nada mais são que "as idéias ou os pensamentos dessas coisas [que] se apresentavam a meu espírito". [...] O erro estava em crer que se tinha um conhecimento que justificasse que havia tais coisas fora da minha mente e de onde advinham estas idéias. (DESCARTES, 1973, p. 108)

No movimento inicial de paroxismo dubitativo, o filósofo francês conclui que nenhuma das razões que se lhe apresentaram para justificar o conhecimento exterior são convincentes e, portanto, que "não foi por um julgamento certo e premeditado, mas apenas por um cego e temerário impulso, que acreditei haver coisas fora de mim, e diferentes de meu ser, as quais [...] imprimem em mim suas semelhanças" (DESCARTES, 1973, p. 111). Como é bem sabido, Descartes seguirá seu itinerário provando a existência do eu pensante e a seguir recorrendo à prova da existência de um Deus verdadeiro, justo e bom que lhe 
assegura a realidade do mundo exterior e a validade das ideias "claras e distintas". Contudo, o deus ex machina não convence muitos.

Poucas derivações dadas ao problema em questão ombreiam, em termos de impacto filosófico, com o idealismo transcendental de Kant. Partiremos, portanto, dessa posição para comparar os ganhos que o conceito de utupë pode aportar à questão. Os fundamentos da epistemologia kantiana são definidos pelas intuições e pelos conceitos

Sejam quais forem o modo e os meios pelos quais um conhecimento se possa referir a objectos, é pela intuição que se relaciona imediatamente com estes e ela é o fim para o qual tende, como meio, todo o pensamento. Esta intuição, porém, apenas se verifica na medida em que o objecto nos for dado; o que, por sua vez, só é possível, [pelo menos para nós homens,] se o objecto afectar o espírito de certa maneira. A capacidade de receber representações (receptividade), graças à maneira como somos afectados pelos objetos, denomina-se sensibilidade. Por intermédio, pois, da sensibilidade são-nos dados objectos e só ela nos fornece intuições; mas é o entendimento que pensa esses objectos e é dele que provêm os conceitos. Contudo, o pensamento tem sempre que referir-se, finalmente, a intuições, quer directamente (directe), quer por rodeios (indirecte) [mediante certos caracteres] e, por conseguinte, no que respeita a nós, por via da sensibilidade, porque de outro modo nenhum objecto nos pode ser dado. ( $\mathrm{KrV}, \mathrm{B} 33)$

A intuição, para Kant, é o modo como a cognição se relaciona imediatamente com os objetos e pode ser de dois tipos: empírica, quando a relação com os objetos se dá por meio de sensações; ou pura, representação a priori, na mente, das formas puras da sensibilidade (espaço e tempo). Seja empírica ou pura, a intuição é condição necessária para que haja qualquer cognição. A intuição pura não será objeto de nossa consideração, por não se relacionar diretamente com o mundo exterior ao sujeito. Ora, se a intuição empírica, que nos põe em contato com os objetos do mundo exterior, o faz por meio de sensações, então tudo o que sabemos acerca dos objetos externos a nós, segundo a epistemologia kantiana, tem origem nas mudanças em nossos estados internos, ou seja, nas sensações que fornecem a matéria do fenômeno, o que leva, forçosamente, ao corolário de que

[...] toda a nossa intuição nada mais é do que a representação do fenómeno; que as coisas que intuímos não são em si mesmas tal como as intuímos, nem as suas relações são em si mesmas constituídas como nos aparecem; e que, se fizermos abstração do nosso sujeito ou mesmo apenas da constituição subjectiva dos sentidos em geral, toda a maneira de ser, todas as relações dos objetos no espaço e no tempo e ainda o espaço e o tempo desapareceriam; pois, como fenómenos, não podem existir em si, mas unicamente em nós. É-nos completamente desconhecida a natureza dos objectos em si mesmos e independentemente de toda esta receptividade da nossa sensibilidade. Conhecemos somente 
o nosso modo de os perceber, modo que nos é peculiar, mas pode muito bem não ser necessariamente o de todos os seres, embora seja o de todos os homens. (KrV, B59)

Chegamos, então, ao ápice de uma das mais estudadas e comentadas teorias representacionais do conhecimento, o idealismo transcendental: nada conhecemos da natureza das coisas em si mesmas, apenas conhecemos as representações subjetivas que delas fazemos, os fenômenos. Mas se o conhecimento se resume a isso, o que garante - caso algo possa ser garantido nesse cenário - que os fenômenos guardam algum vínculo efetivo com as coisas de que supostamente são representações? Se "nem o mais claro conhecimento dos fenômenos, único que nos é dado, nos proporcionaria o conhecimento do que os objetos podem ser em si mesmos" (KrV, B60), não é hora de imolar simultaneamente a ontologia e a epistemologia no altar do ceticismo?

Para evitar o que nos parece um obstáculo absoluto à aspiração cognitiva mais elementar e intuitiva do homem, a de saber afinal o que existe no mundo ao seu redor, seria preciso demonstrar que por algum tipo de harmonia estabelecida o conteúdo das representações de um sujeito é tal qual as determinações das coisas em si mesmas - ou seja, algo que, de alguma forma, garanta a objetividade dos conteúdos que a mente forma a partir da afecção sensível. Valendo-nos de concepções apresentadas por Kopenawa em A queda do céu, somos capazes de conjecturar a respeito de nosso próprio paradigma teórico com novas ideias que o revisam e enriquecem, de modo a enfrentar as dificuldades epistemológicas colocadas pelo subjetivismo moderno quanto à possibilidade de conhecermos as coisas externas à mente do sujeito cognoscente.

Com base nas exposições cosmo-ontológicas xamânicas, é possível postular uma tese sobre a relação das imagens com seus respectivos representantes corpóreos, de modo tal que chegamos à ideia de uma intuição sobrenatural que, se transposta ao paradigma filosófico representacional, proporcionaria a referida garantia necessária da objetividade de nossas representações. Cumpre ressaltar que essa tese não é sustentada explicitamente nas palavras de Kopenawa, mas delas pode ser derivada sem contradição com o pensamento xamânico apresentado em A queda do céu.

\subsection{A intuição sobrenatural como acesso direto às coisas em si mesmas}


O poder conceitual de utupë é bem exemplificado na triangulação ontológica yarorixapiri-yaro, cuja riqueza de derivações só se mantém coesa ao gravitar em torno daquele conceito

\begin{abstract}
As imagens que os xamãs fazem dançar não são dos animais que caçamos. São de seus pais, que passaram a existir no primeiro tempo. São, como disse, as imagens dos ancestrais animais que chamamos yarori. Há muito e muito tempo, quando a floresta ainda era jovem, nossos antepassados, que eram humanos com nomes de animais, se metamorfosearam em caça. [...] De modo que são esses ancestrais tornados outros que caçamos e comemos hoje em dia. As imagens que fazemos descer e dançar como xapiri, por outro lado, são suas formas de fantasma. São seu verdadeiro coração, seu verdadeiro interior. Os ancestrais humanos do primeiro tempo não desapareceram, portanto. Tornaram-se os animais de caça que moram na floresta hoje. Mas seus fantasmas também continuam existindo. Continuam tendo seus nomes de animais, mas agora são seres invisíveis. Transformaram-se em xapiri que são imortais (KOPENAWA; ALBERT, 2015, p. 117).
\end{abstract}

O ser dos yarori, ou ancestrais animais, desdobrou-se, portanto, numa díade formada pelos yaro, os animais visíveis da floresta, e os xapiri, que são ao mesmo tempo os fantasmas transformados dos yarori e o verdadeiro coração ou verdadeiro interior dos yaro. Os xapiri são a continuidade, metamorfoseada, da utupë dos ancestrais animais, e os yaro são o aspecto material ou corpóreo, chamado por Kopenawa de pele (siki), daqueles mesmos ancestrais. Conforme explica Albert: "Trata-se aqui da 'pele' enquanto 'invólucro corporal' (siki) oposta à 'imagem' (utupë) interior, sede da energia e da identidade corporal" (KOPENAWA; ALBERT, 2015, p. 621, nota 18).

Desse exemplo da cosmologia Yanomami desejamos ressaltar a superioridade ontológica e epistemológica da utupë sobre a sikí. No que tange à ontologia, Kopenawa (2015, p. 116) destaca em vários momentos a superioridade das imagens em relação às peles, como quando afirma que elas são "o verdadeiro centro, o verdadeiro interior dos animais que caçamos". Esses animais seriam chamados pelos brancos (napë) de "representantes" das imagens, ou, ainda mais claramente, estes diriam que os animais da floresta "não fazem senão imitar suas imagens" (KOPENAWA; ALBERT, 2015, p. 116) Ademais, encontramos a descrição das imagens existindo sem um correspondente material, como nas passagens em que Kopenawa $(2015$, p. $86 ; 119)$ relata que "o filho de Omama, hoje, está morto. Sua imagem, porém, ainda existe", ou que Omama, depois de ter criado os brancos, morreu "e, hoje, apenas sua imagem, na forma de fantasma, continua existindo". Mas não temos relatos, no texto em apreço, de existirem seres corpóreos sem imagem; ao contrário, lemos claramente que todos "os seres da floresta possuem uma imagem utupë", e o escopo 
dessa afirmação se pretende universal, pois os caminhos dos xapiri se "bifurcam, se cruzam e até se superpõem, para muito além dela, por toda a vasta terra a que chamamos urihi a pree ou urihi a pata e que os brancos chamam de mundo inteiro" (KOPENAWA; ALBERT, 2015, p. 116). A ubiquidade da utupë fica explícita quando Kopenawa explica o funcionamento dos "gravadores dos brancos, nos quais Omama também colocou uma imagem de árvore de cantos" (2015, p. 114).

A precedência ontológica das imagens também pode ser observada na agência de Omama, que, ao criar ou destruir seres, o faz agindo sobre imagens

Por isso Omama teve de criar uma nova floresta, mais sólida, cujo nome é Hutukara. [...] Omama fixou a imagem dessa nova terra e esticou-a aos poucos, cuidadosamente, do mesmo modo como espalhamos o barro para fazer placas de cerâmica mahe. [...] Também desenhou o primeiro sol, para nos dar luz. Mas era por demais ardente e ele teve de rejeitá-lo, destruindo sua imagem. Então, criou aquele que vemos hoje no céu. (KOPENAWA; ALBERT, 2015, p. 81, grifos nossos nas passagens não onomásicas)

A universalidade das imagens e sua característica de precedência ontológica sobre os aspectos sensíveis "define o mundo dos simulacros" e "coloca o próprio mundo como fantasma" (DELEUZE, A lógica do sentido, apud VALENTIM, 2018, p. 222). A prioridade epistêmica que os xamãs dão às imagens demonstramos na seção 2.1 deste trabalho, em diversos passos do texto nos quais o contato com os xapiri representa o aprendizado das "coisas de verdade". Tal relevância epistêmica é notável quando Kopenawa (2015, p. 487) confidencia qual seria seu maior anseio: “Quero me tornar espírito e continuar estudando com os xapiri. Só quero adquirir mais conhecimento!"”.

Com base no sentido ontoepistêmico forte de utupë e na potencialidade patente nos xamãs (mas a nosso ver não interditada à humanidade) de libertar sua imagem do invólucro corporal e ter acesso direto às imagens de outros entes, propomos a expressão intuição sobrenatural como o modo de a cognição se relacionar imediatamente não a objetos, mas a seres, ao verdadeiro interior dos entes. Segundo propomos, a título de hipótese, tal intuição sobrenatural decorre diretamente do que Albert designou por visão xamânica

As "pessoas comuns" kuapora thë pë (literalmente "gente que simplesmente existe") são aqui contrapostas aos xamãs, xapiri thë pë (literalmente "gente espírito"). Estes atribuem àquelas "olhos de fantasma", pois só são capazes de ver a aparência enganosa dos seres e dos fenômenos. A visão xamânica, em compensação, dá acesso à imagem-essência dos entes (utupë) no tempo de sua criação mítica. Essa forma-imagem é denotada pelo sufixo -ri (pl. -ri pë). O conceito de utupë designa 
igualmente a imagem corpórea interior/essência vital dos seres animados atuais. (KOPENAWA; ALBERT, 2015, p. 615, nota 11)

Muito distinta da intuição empírica aos moldes kantianos, relacionada com objetos cuja natureza do que são em si mesmos será sempre completamente desconhecida, a intuição sobrenatural se relaciona diretamente com a essência dos seres, e a cognição oriunda não é uma produção imposta a priori por nossa estrutura conceitual, mas um verdadeiro conhecer por assimilação ontológica do ser conhecido. Aqui, a intuição sobrenatural que derivamos da filosofia Yanomami conforme exposta por Kopenawa pode ser diretamente relacionada à intuição no sentido dado por Bergson de "conhecimento íntimo do espírito pelo espírito, [e] subsidiariamente o conhecimento, pelo espírito, do que há de essencial na matéria" (BERGSON, 1984, p. 33, nota 6). É o conhecer por dentro (dedans) bergsoniano.

A fundamentação última do conhecimento conferida pela intuição sobrenatural, por conseguinte, permitiria a total superação da oposição sujeito-objeto, verdadeira fratura ontognoseológica da tradição filosófica moderna, por meio da potencialidade metamórfica da utupë que conhece o outro tornando-se o outro. Assumindo tal hipótese, o xamanismo mostra que há instâncias em que conhecemos as coisas em si mesmas, refutando a tese do idealismo transcendental e superando o ceticismo epistemológico moderno dele derivado.

\section{CONCLUSÃO}

Procuramos demonstrar no presente trabalho que a leitura da obra A queda do céu permite uma interpretação do conceito de utupë capaz de enriquecer o debate filosófico da tradição ocidental, notadamente quanto a um problema que o assola desde a Antiguidade e que se tornou crucial com os modernos: o ceticismo epistemológico. Tentamos construir a proposta derivada da letra do texto de Kopenawa - de sua pele de imagens -, bem como de alguns de seus principais comentadores, de modo a assumir certas consequências que são tão filosoficamente radicais quanto comprometidas com a verdade das palavras dadas pelo autor xamã. Contudo, um passo a mais pode ser dado em uma investigação futura, cuja direção, neste ponto, desejamos apenas mencionar.

Visto que o referido mecanismo de intuição sobrenatural garantiria a possibilidade de conhecer as coisas em si mesmas apenas àqueles capazes de acessar seu estado de fantasma, caberia uma investigação para averiguar se no texto de Kopenawa há algo 
que embase uma relação imagética atuante na percepção ordinária dos representantes corpóreos, mesmo sem que o percipiente esteja cônscio dela. Desse modo, seria possível postular uma tese ainda mais forte, de aplicação epistêmica mais ampla, na qual uma rigorosa transposição do conceito de utupë para o paradigma representacional permitiria afirmar que toda representação é, em seu nível mais fundamental, garantida pela apreensão dos seres-imagens. Haveria, então, uma intuição natural (que subsume a intuição empírica) por meio da qual os "olhos de fantasma" (ou em estado ordinário de percepção) das pessoas comuns (kuapora thë pë) veriam os representantes corpóreos de um ser concomitantemente à apreensão que suas utupë estariam fazendo da utupë do ser. As representações mentais de algo não seriam, assim, produções inteiramente subjetivas da mente sensivelmente afetada por algo, na medida em que a apreensão seria espiritual e se caracterizaria pela comunhão interimagética na qual um ser, enquanto imagem, se conectaria à imagem-essência dos entes, que, sendo intrinsecamente conectada a eles, tem caráter objetivo.

Esse esboço de uma tese ainda mais arrojada do que a apresentada ao longo do trabalho apenas demonstra a fecundidade do estudo da filosofia Yanomami. O fato de que Davi Kopenawa tenha, em certa medida, efetuado uma transformação em nossa direção, a dos napë, para nos trazer o melhor de seu conhecimento com o intuito de que nos tornemos mais sensatos, demonstra que a via metamórfica pode ser bidirecional, de modo a podermos nos transformar em outros em sua direção e metamorfosear nossa filosofia em algo mais aberto a todas as possibilidades de experimentar o real. 


\section{REFERÊNCIAS BIBLIOGRÁFICAS}

ALBERT, B. Yanomami: retour sur image(s). In: Fondation Cartier trente ans pour l'art contemporain, vol. 2. Paris: Fondation Cartier, 2014. p. 237-248.

BERGSON, H. Introdução à metafísica. In: Coleção os pensadores, Bergson. Trad. Franklin Leopoldo e Silva e Nathanael Caxeiro. São Paulo: Abril Cultural, 1984. p. 13-39.

BORGES, J. L. Historia de la eternidad. Buenos Aires: Debolsillo, 2011.

DESCARTES, R. Meditações. In: Coleção os pensadores, vol. XV. Trad. J. Guinsburg e Bento Prado Júnior. São Paulo: Abril Cultural, 1973. p. 81-150.

KANT, I. Crítica da razão pura. Trad. Manuela Pinto dos Santos e Alexandre Fradique Morujão. Lisboa: Fundação Calouste Gulbenkian, 1989.

KOPENAWA, D.; ALBERT. B. A queda do céu: palavras de um xamã yanomami. Trad. Beatriz Perrone-Moisés. São Paulo: Companhia das Letras, 2015.

PLATÃO. A República. 11 ed. Trad. Maria Helena da Rocha Pereira. Lisboa: Fundação Calouste Gulbenkian, 2008.

VALENTIM, M. A. Extramundanidade e sobrenatureza: ensaios de ontologia infundamental. Florianópolis: Cultura e Barbárie Editora, 2018.

VIVEIROS DE CASTRO, E. O recado da mata. Prefácio. In: KOPENAWA, D.; ALBERT. B. A queda do céu: palavras de um xamã yanomami. Trad. Beatriz Perrone-Moisés. São Paulo: Companhia das Letras, 2015. p. 11-41. 